\title{
Hydrogen sulfide attenuates doxorubicin-induced cardiotoxicity by inhibiting the expression of peroxiredoxin III in H9c2 cells
}

\author{
MI-HUA LIU ${ }^{1}$, XIAO-LONG LIN ${ }^{2 *}$, CONG YUAN ${ }^{3 *}$, JUN HE ${ }^{1}$, TIAN-PING TAN ${ }^{1}$, SHAO-JIAN WU ${ }^{1}$, SHAN YU $^{1}$,

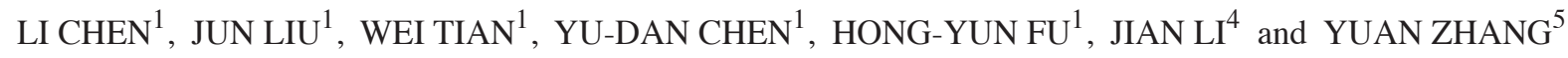 \\ ${ }^{1}$ Department of Clinical Laboratory, Affiliated Nanhua Hospital, University of South China, Hengyang, Hunan 421001; \\ ${ }^{2}$ Department of Pathology, Affiliated Huizhou Hospital of Guangzhou Medical University, \\ The Third People's Hospital of Huizhou, Huizhou, Guangdong 516002; ${ }^{3}$ Department of Cardiology, \\ The First Hospital of Changsha, Changsha, Hunan 410005; ${ }^{4}$ Department of Ultrasonic Diagnosis, \\ Bo'ai Hospital of Zhongshan, Zhongshan, Guangdong 528403; ${ }^{5}$ Department of Pathology, \\ Mawangdui Hospital, Changsha, Hunan 410016, P.R. China
}

Received January 9, 2015; Accepted October 20, 2015

DOI: $10.3892 / \mathrm{mmr} .2015 .4544$

\begin{abstract}
Doxorubicin (DOX) is a widely used chemotherapeutic agent, which can give rise to severe cardiotoxicity, limiting its clinical use. Preliminary evidence suggests that hydrogen sulfide $\left(\mathrm{H}_{2} \mathrm{~S}\right)$ may exert protective effects on DOX-induced cardiotoxicity. Therefore, the aim of the present study was to investigate whether peroxiredoxin III is involved in the cardioprotection of $\mathrm{H}_{2} \mathrm{~S}$ against DOX-induced cardiotoxicity. The results demonstrated that DOX not only markedly induced injuries, including cytotoxicity and apoptosis, it also increased the expression levels of peroxiredoxin III. Notably, pretreatment with sodium hydrosulfide significantly attenuated the DOX-induced decrease in cell viability and increase in apoptosis, and also reversed the increased expression levels of peroxiredoxin III in $\mathrm{H} 9 \mathrm{c} 2$ cardiomyocytes. In addition, pretreatment of the $\mathrm{H} 9 \mathrm{c} 2$ cells with $\mathrm{N}$-acetyl-L-cysteine, a scavenger of reactive oxygen species, prior to exposure to DOX markedly decreased the expression levels of peroxiredoxin III. In conclusion, the results of the present study suggested that exogenous $\mathrm{H}_{2} \mathrm{~S}$ attenuates DOX-induced cardiotoxicity by inhibiting the expression of peroxiredoxin III in H9c2 cells. In the present study, the apoptosis of $\mathrm{H} 9 \mathrm{c} 2$ cardiomyocytes
\end{abstract}

Correspondence to: Mr. Mi-Hua Liu, Department of Clinical Laboratory, Affiliated Nanhua Hospital, University of South China, 336 Dongfeng South Road, Hengyang, Hunan 421001, P.R. China E-mail:mihualiu@163.com

Miss. Yuan Zhang, Department of Pathology, Mawangdui Hospital, 91 Guhan Road, Changsha, Hunan 410016, P.R. China

E-mail: 604747341@qq.com

*Contributed equally

Key words: hydrogen sulfide, peroxiredoxin III, apoptosis, cardiomyocytes was assessed using an methyl thiazolyl tetrazolium assay and Hoechst staining. The levels of Prx III and cystathionine- $\gamma$ lyase were examined by western blotting.

\section{Introduction}

Doxorubicin (DOX) is an anthracycline antibiotic, which is used to treat various types of neoplastic disease in humans (1). However, the use of DOX clinically is limited by severe toxic side-effects on the heart, which can lead to dilated cardiomyopathy and congestive heart failure (2). Several studies have shown that the production of reactive oxygen species (ROS) is implicated in DOX cardiotoxicity, which eventually leads to endothelial dysfunction $(3,4)$ and cardiomyocyte apoptosis (5). A number of pharmacological interventions have been suggested as therapies to inhibit DOX-induced cardiotoxicity (6-8).

Hydrogen sulfide $\left(\mathrm{H}_{2} \mathrm{~S}\right)$ has long bee considered a toxic gas, however, it has now been qualified as the third gasotransmitter, along with nitric oxide and carbon monoxide, exerting various effects in the cardiovascular system (9-11). $\mathrm{H}_{2} \mathrm{~S}$ has been shown to protect the heart from myocardial ischemia-reperfusion injury in various studies $(12,13)$. Our previous study demonstrated that increased endogenous $\mathrm{H}_{2} \mathrm{~S}$ generation in the early reperfusion phase is important in ischemia preconditioning (IPC)-elicited protection in isolated hearts (11).

Various antioxidant signaling pathways protect or regulate the response of cells to oxidative stress $(14,15)$. Several antioxidants, including peroxiredoxins (Prxs), are oxidized in cells treated with ROS. Prxs are a recently characterized family of antioxidant enzymes, which control the expression levels of cytokine-induced peroxide and mediate signal transduction in mammalian cells (16). Multiple mammalian Prxs (I-VI) often coexist in the same cell in various intracellular locations and function as scavengers of cellular $\mathrm{H}_{2} \mathrm{O}_{2}$, which are released following stimulation with growth factors during proliferation, apoptosis or oxidative stress $(17,18)$. Furthermore, the expression levels of Prxs are high in the heart and there has been 
increasing interest in their importance in the cardiac response to oxidative stress (19). Notably, Prx III has a protective role in cisplatin- and gentamicin-induced apoptosis through a mitochondria-dependent signaling pathway (20). The overexpression of Prx III protects the mouse myocardium from infarction (21). By contrast, the depletion of Prx III results in increased intracellular expression levels of $\mathrm{H}_{2} \mathrm{O}_{2}$ and sensitizes cells to apoptotic signaling (22).

In the present study, H9c2 cells were treated with $5 \mu \mathrm{M}$ DOX to establish a chemotherapy-induced cardiotoxicity model (6). This model was then used to investigate whether DOX induces the expression of Prx III in the H9c2 cells, and to examine the role of Prx III in the protective effect of $\mathrm{H}_{2} \mathrm{~S}$ against DOX-induced injury in $\mathrm{H} 9 \mathrm{c} 2$ cells.

\section{Materials and methods}

Materials. Methyl thiazolyl tetrazolium (MTT), Hoechst 33258, DOX, sodium hydrosulfide (NaHS) and N-acetyl-L-cysteine (NAC) were purchased from Sigma-Aldrich (St. Louis, MO, USA). All cell culture medium components were purchased from Thermo Fisher Scientific, Inc. (Waltham, MA, USA), unless otherwise specified. The H9c2 cardiomyocytes were purchased from the Shanghai Cell Library of China, which were originally obtained from the American Type Culture Collection (Manassas, VA, USA).

Cell culture. The H9c2 cardiomyocytes were cultured in Dulbecco's modified Eagle's medium (DMEM; Beyotime Institute of Biotechnology, Shanghai, China) supplemented with $10 \%$ fetal bovine serum (FBS; Beyotime Institute of Biotechnology), $100 \mu \mathrm{g} / \mathrm{ml}$ streptomycin (Gibco; Thermo Fisher Scientific, Inc.) and $100 \mathrm{U} / \mathrm{ml}$ penicillin (Gibco; Thermo Fisher Scientific, Inc.) in a humidified atmosphere containing $5 \% \mathrm{CO}_{2}$ at $37^{\circ} \mathrm{C}$, and the cells were passaged every 2 days. The $\mathrm{H} 9 \mathrm{c} 2$ cardiomyocytes were seeded at a density of $2 \times 10^{6}$ cells/dish into $100 \mathrm{~mm}$ dishes containing $10 \% \mathrm{FBS}$, and incubated at $37^{\circ} \mathrm{C}$ for $24 \mathrm{~h}$, following which the medium was replaced with $0.5 \%$ DMEM supplemented with FBS for $24 \mathrm{~h}$ starvation.

MTT assay. The MTT assay, which is a standard method used to assess the viability of cells, was performed in the present study. Prior to each experiment, the H9c2 cardiomyocytes $\left(5 \times 10^{3}\right.$ cells/well) were seeded into 96 -well microtitre plates. Following incubation with NAC for $60 \mathrm{~min}$ and/or NaHS for $30 \mathrm{~min}$ at $37^{\circ} \mathrm{C}$, the cells were treated with $5 \mu \mathrm{M}$ DOX for a further $24 \mathrm{~h}$. Subsequently, $10 \mu \mathrm{l}$ MTT solution was added to each of the wells, and the plates were incubated for $4 \mathrm{~h}$ at $37^{\circ} \mathrm{C}$. The absorbance was then measured at $470 \mathrm{~nm}$ using a SpectraMax 190 spectrophotometer (Molecular Devices, Sunnyvale, CA, USA), and used to calculate the relative ratio of cell viability. Three independent experiments were performed for each experimental condition.

Assessment of cardiomyocyte cell apoptosis. The levels of apoptosis were analyzed using fluorescence microscopy following staining of the cells with Hoechst 33258 chromatin dye. Following the treatments described above, the cells were fixed with ice-cold $4 \%$ paraformaldehyde dissolved in phosphate-buffered saline (PBS) at room temperature for
20 min. Non-specific binding was blocked using 5\% normal goat serum (Sigma-Aldrich) in 0.01 M PBS containing $0.3 \%$ Triton X-100. The cells were then washed twice with PBS and incubated with $10 \mu \mathrm{g} / \mathrm{ml}$ Hoechst 33258 for $10 \mathrm{~min}$ at room temperature in the dark. The cells were visualized under a fluorescence microscope (BX50-FLA; Olympus Corporation, Tokyo, Japan). Apoptotic cells exhibited condensed, fractured or distorted nuclei, whereas viable cells exhibited normal nuclear size and uniform fluorescence. The apoptotic rate was analyzed with a cell counter in Image J 1.4 software (National Institutes of Health, Bethesda, MD, USA).

Western blot analysis. The cells were homogenized directly using cell lysis buffer (Cell Signaling Technology, Inc., Danvers, MA, USA) and the lysates were centrifuged at $12,000 \mathrm{x}$ g for $10 \mathrm{~min}$ at $4^{\circ} \mathrm{C}$. Protein concentrations were determined with the use of a Bicinchoninic Acid Protein Assay kit (Beyotime Institute of Biotechnology), according to the manufacturer's protocol. The extracted proteins (30 $\mu \mathrm{g})$ were mixed with 5\% SDS sample buffer (Beyotime Institute of Biotechnology) prior to being boiled at $100^{\circ} \mathrm{C}$ for $7 \mathrm{~min}$ and separated by electrophoresis on a $10 \%$ SDS-PAGE. Following electrophoresis, the proteins were transferred onto polyvinylidene difluoride membranes (Beyotime Institute of Biotechnology). The membranes were blocked in Tris-buffered saline with $0.1 \%$ Tween 20 (TBS-T), containing $5 \%$ non-fat dried milk for $2 \mathrm{~h}$ at room temperature with agitation. Following blocking, the membranes were incubated with the following antibodies: Rabbit anti-Prx III polyclonal antibody (cat. no. ab73349; 1:400; Abcam, Cambridge, UK; $1: 400$, rabbit anti-cystathionine- $\gamma$-lyase (CSE) monoclonal antibody (cat. no. 12217-1-AP; 1:1,000; Proteintech Group, Inc., Chicago, IL, USA) and GAPDH (cat. no. AG019; dilution 1:1,000; Beyotime Institute of Biotechnology (Shanghai, China). Subsequently, the membranes were incubated with $5 \%$ milk or bovine serum albumin overnight at $4^{\circ} \mathrm{C}$. Primary antibody was removed by washing the membranes three times in TBS-T, and incubated for $2 \mathrm{~h}$ with the appropriate horseradish peroxidase-conjugated secondary antibody (cat. no. A0208; 1:1,000; Beyotime Institute of Biotechnology). Following three washes in TBS-T, the antigen-antibody bands were detected using an enhanced chemiluminescence kit (Beyotime Institute of Biotechnology) and quantified using a densitometry software program (Quantity One; Bio-Rad Laboratories, Hemel Hempstead, UK) and GAPDH was used as a loading control.

Statistical analysis. The results of the present study are presented as the mean \pm standard error of the mean. Statistical analysis was performed using Student's t-test or one-way analysis of variance with SPSS 13.0 (SPSS, Inc., Chicago, IL, USA). P<0.05 was considered to indicate a statistically significant difference.

\section{Results}

DOX increases the expression levels of Prx III in H9c2 cells. in a time-dependent manner. To examine the effect of DOX on the expression levels of Prx III, the H9c2 cells were treated with $5 \mu \mathrm{M}$ DOX for the indicated time periods $(0,3,6,12$ and $24 \mathrm{~h})$. The results of the western blot analysis demonstrated that DOX increased the expression levels in of Prx III a time-dependent manner (Fig. 1). 


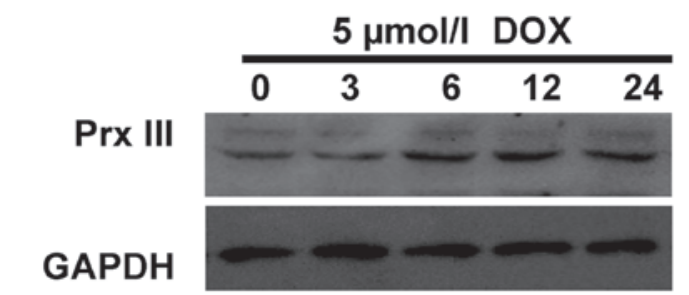

B

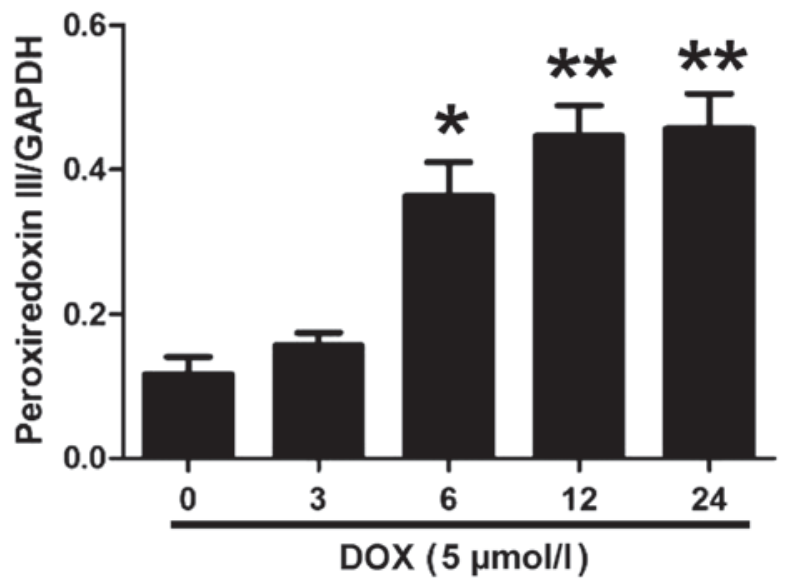

Figure 1. DOX increases the expression levels of of Prx III in H9c2 cells (A) Expression levels of of Prx III were analyzed using immunoblotting. (B) Relative expression levels of Prx III were determined using blot densitometry. The data are presented as the mean \pm standard error of the mean $(\mathrm{n}=3) .{ }^{*} \mathrm{P}<0.05$ and ${ }^{* *} \mathrm{P}<0.01$ vs. control $(0 \mu \mathrm{mol} / \mathrm{l})$ group. DOX, doxorubicin; Prx, peroxiredoxin.

DOX inhibits the expression and activity of CSE in $\mathrm{H} 9 \mathrm{c} 2$ cells. $\mathrm{CSE}$ is the enzyme responsible for endogenous $\mathrm{H}_{2} \mathrm{~S}$ generation in $\mathrm{H} 9 \mathrm{c} 2$ cells (23). Western blot analysis was performed to evaluate whether DOX decreases endogenous $\mathrm{H}_{2} \mathrm{~S}$ production by inhibiting the expression of CSE. As shown in Fig. 2, treatment with $5 \mu \mathrm{M}$ DOX for the indicated time periods $(0$, $3,6,12$ and $24 \mathrm{~h}$ ) caused a significant downregulation in the expression of CSE in the H9c2 cells. These results suggested that DOX induced CSE inhibition in the H9c2 cells, which contributed to a decrease in endogenous $\mathrm{H}_{2} \mathrm{~S}$ production.

Exogenous $\mathrm{H}_{2} \mathrm{~S}$ inhibits DOX-induced expression of Prx III in $\mathrm{H} 9 \mathrm{c} 2$ cells. To determine whether the protective effect of $\mathrm{H}_{2} \mathrm{~S}$ against the toxicity induced by DOX was associated with the inhibition of Prx III, the effects of NaHS on the expression levels of Prx III induced by DOX were evaluated. Pretreatment of the H9c2 cells with $100 \mu \mathrm{mol} / 1 \mathrm{NaHS}$ (a donor of $\mathrm{H}_{2} \mathrm{~S}$ ) for $30 \mathrm{~min}$ prior to exposure to $5 \mu \mathrm{mol} / 1 \mathrm{DOX}$ for $24 \mathrm{~h}$ significantly inhibited the DOX-induced overexpression of Prx III (Fig. 3). NaHS did not affect the basal expression levels of Prx III in the H9c2 cells when treated alone. These results suggested that the inhibition of Prx III may be involved in the cryoprotective effects of $\mathrm{H}_{2} \mathrm{~S}$ from DOX-induced cytotoxicity in $\mathrm{H} 9 \mathrm{c} 2$ cells.

NAC reverses the DOX-induced decrease of Prx III in $\mathrm{H} 9 \mathrm{c} 2$ cells. To determine whether the inhibitory effect of NaHS on the DOX-induced increased expression of Prx III was associated with its antioxidant properties, the $\mathrm{H} 9 \mathrm{c} 2$ cells were pretreated with 1,000 $\mu \mathrm{M} \mathrm{NAC}$, a ROS scavenger, for $60 \mathrm{~min}$,
A

\begin{tabular}{lllll}
\multicolumn{5}{c}{$5 \mu \mathrm{mol} / \mathrm{L}$} \\
\hline 0 & 3 & 6 & 12 & 24
\end{tabular}

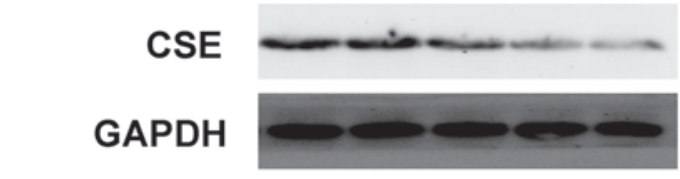

B

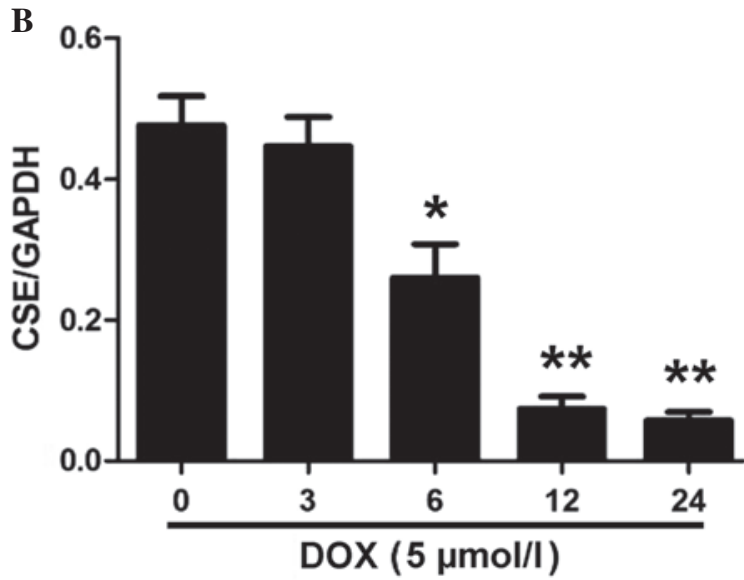

Figure 2. Inhibitory effects of DOX on the expression levels of CSE in H9c2 cells. (A) Expression levels of CSE were analyzed using immunoblotting. (B) Relative expression levels of CSE were determined using blot densitometry. Data are presented as the mean \pm standard error of the mean $(n=3) .{ }^{*} \mathrm{P}<0.05$ and ${ }^{* *} \mathrm{P}<0.01$ vs. control $(0 \mu \mathrm{mol} / 1)$ group. DOX, doxorubicin; CSE, choreoathetosis/spasticity, episodic.

A Control DOX NaHS DOX+NaHS

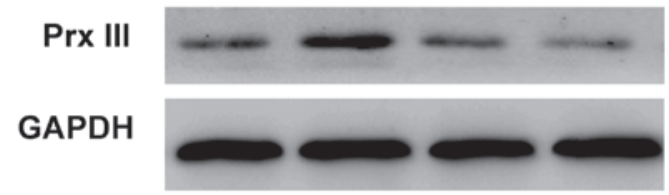

B

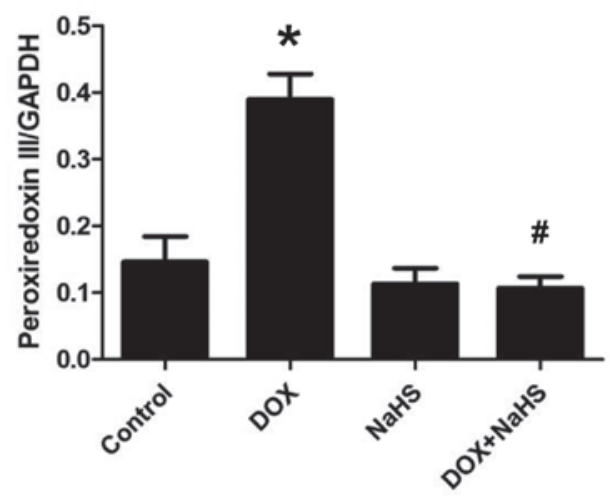

Figure 3. Exogenous $\mathrm{H}_{2} \mathrm{~S}$ decreases the DOX-induced expression levels of Prx III in H9c2 cells. (A) Expression levels of Prx III were analyzed using immunoblotting. (B) Relative expression levels of Prx III were determined using blot densitometry. The data are presented as the mean \pm standard error of the mean $(\mathrm{n}=3) .{ }^{*} \mathrm{P}<0.05$, vs. control group; ${ }^{*} \mathrm{P}<0.05$, vs. DOX-treated group. DOX, doxorubicin; $\mathrm{H}_{2} \mathrm{~S}$, hydrogen sulfide; Prx, peroxiredoxin.

following which the cells were exposed to $5 \mu \mathrm{M}$ DOX for $24 \mathrm{~h}$. As shown in Fig. 4, similar to the inhibitory effect of pretreatment of cells with NaHS, pretreatment of the H9c2 cells with 
A

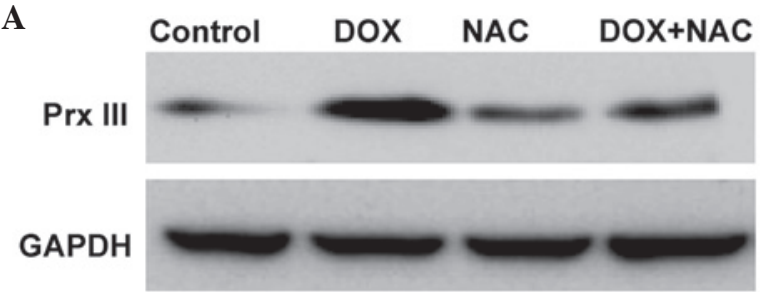

B

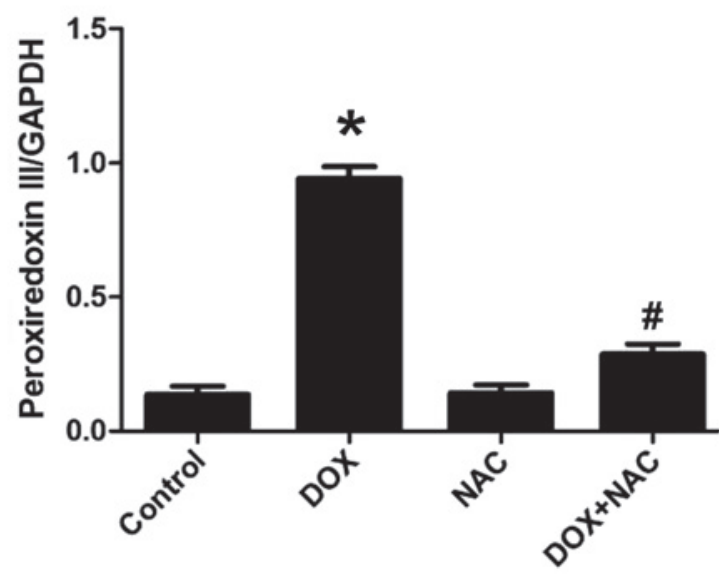

Figure 4. Effect of NAC on the expression of Prx III induced by DOX in H9c2 cells. (A) Expression levels of Prx III were analyzed using immunoblotting. (B) Relative levels of Prx III were determined using blot densitometry. The data are presented as the mean \pm standard error of the mean $(n=3)$. ${ }^{*} \mathrm{P}<0.05$, vs. control group; ${ }^{\text {P }}<0.05$, vs. DOX-treated group; DOX, doxorubicin; NAC, N-acetyl-L-cysteine; Prx, peroxiredoxin.

NAC for 60 min significantly decreased the expression levels of Prx III. These results suggested that the inhibitory properties of $\mathrm{H}_{2} \mathrm{~S}$ on the DOX-induced expression of Prx III involved the contribution of an antioxidant effect.

Exogenous $\mathrm{H}_{2} \mathrm{~S}$ inhibits DOX-induced cytotoxicity. As shown in Fig. 5, exposure of the H9c2 cells to DOX at $5 \mu \mathrm{M}$ for $24 \mathrm{~h}$ induced significant cytotoxicity, resulting in a reduction in the viability of the cells. However, pretreatment of the cells with $100 \mu \mathrm{M}$ NaHS for 30 min prior to exposure to DOX significantly reduced the effects of DOX-induced cytotoxicity, which was demonstrated by an increase in the viability of the cells. Pretreatment of the cells with NAC had a similar protective effect as $\mathrm{H}_{2} \mathrm{~S}$ against DOX-induced cytotoxicity, also suggesting the involvement of an antioxidant effect against the cytotoxicity induced by DOX. Treatment with either NaHS or NAC alone did not affect the viability of the H9c2 cells.

Exogenous $\mathrm{H}_{2} \mathrm{~S}$ reduces DOX-induced apoptosis in $\mathrm{H} 9 \mathrm{c} 2$ cells. The effects of NaHS and NAC on DOX-induced apoptosis were further investigated in the present study. As shown in Fig. 6, the $\mathrm{H} 9 \mathrm{c} 2$ cells treated with $5 \mu \mathrm{M}$ DOX for $24 \mathrm{~h}$ exhibited characteristics typical of apoptosis, including the condensation of chromatin, nuclear shrinkage and the presence of apoptotic bodies. However, pretreatment of the H9c2 cells with $100 \mu \mathrm{M}$ NaHS for 30 min prior to DOX exposure significantly decreased the DOX-induced increase in cells exhibiting nuclear condensation and fragmentation. In addition, the H9c2 cells were preconditioned with the ROS scavenger, NAC $(1,000 \mu \mathrm{M})$ prior to exposure to DOX. The results demonstrated that pretreatment

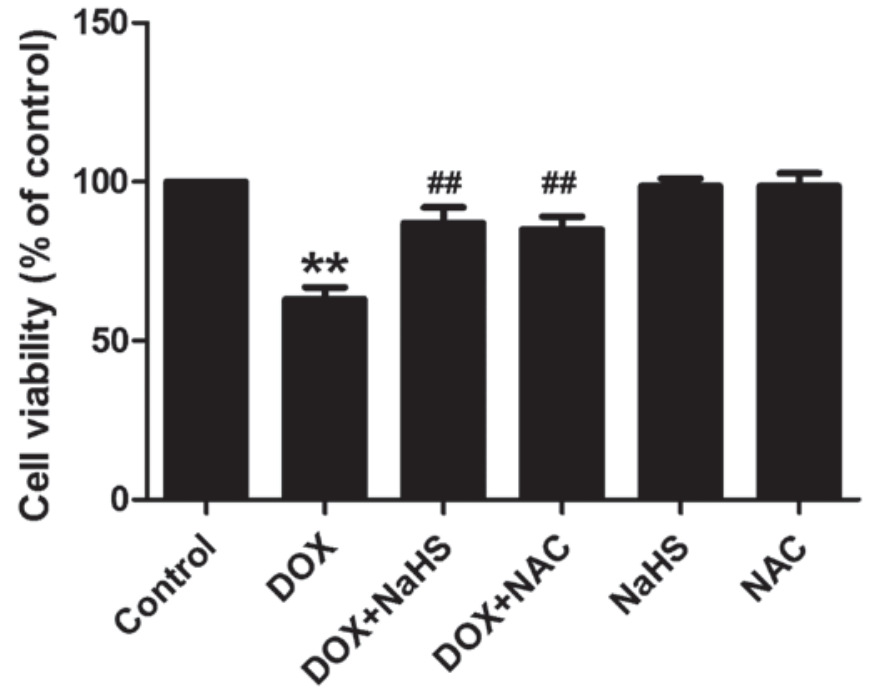

Figure 5. Exogenous $\mathrm{H}_{2} \mathrm{~S}$ and NAC protect $\mathrm{H} 9 \mathrm{c} 2$ cells against DOX-induced cytotoxicity. The viability of the cells in the different treatment groups were measured using a methyl thiazolyl tetrazolium assay. The data are presented as the mean \pm standard error of the mean $(n=3)$. ${ }^{* *} \mathrm{P}<0.01$, vs. control group; ${ }^{\# \#} \mathrm{P}<0.01$, vs. DOX-treated group; DOX, doxorubicin; NAC, $\mathrm{N}$-acetyl-L-cysteine; NaHS, sodium hydrosulfide.

of the cells with NAC significantly attenuated DOX-induced H9c2 cell apoptosis. Treatment with NaHS or NAC alone did not have a marked effect on the morphology of the cells, or on the number of apoptotic H9c2 cells identified. These findings suggested that antioxidant properties are involved in, and contribute to, the inhibitory effects of $\mathrm{H}_{2} \mathrm{~S}$ on the DOX-induced apoptosis of $\mathrm{H} 9 \mathrm{c} 2$ cells.

\section{Discussion}

Several studies have demonstrated that the major molecular mechanism underlying DOX-induced cardiotoxicity are free radical-induced oxidative stress and cardiomyocyte death caused by apoptosis and necrosis $(6,24)$. Concordant with previous studies $(24,25)$, the present study demonstrated that exposure of H9c2 cells to DOX markedly increased cellular injury, decreased cell viability, increased cell apoptosis and increased the expression levels of Prx III.

A previous study demonstrated the cardioprotective effects of $\mathrm{H}_{2} \mathrm{~S}$ in animal models of disease (26). Treatment with $\mathrm{H}_{2} \mathrm{~S}$ significantly reduced myocardial infarct size, improved regional left ventricular function, and increased endothelium-dependent and endothelium-independent microvascular reactivity in a porcine model of myocardial ischemia-reperfusion (27). In addition, $\mathrm{H}_{2} \mathrm{~S}$ has been observed to attenuate myocardial necrosis and apoptosis (28). Endogenous $\mathrm{H}_{2} \mathrm{~S}$ has been associated with cardioprotection, enabled via metabolic inhibition preconditioning in rat ventricular myocytes (29). The inhibition of the production of endogenous $\mathrm{H}_{2} \mathrm{~S}$ by its synthesis inhibitor, DL-propargylglycine, has been observed to inhibit the protective effects of IPC in isolated hearts and cardiomyocytes (30). In the present study, H9c 2 cells were used to investigate the effects of DOX on endogenous $\mathrm{H}_{2} \mathrm{~S}$ generation. The results demonstrated that exposure of the $\mathrm{H} 9 \mathrm{c} 2$ cells to DOX led to a significant decrease in $\mathrm{H}_{2} \mathrm{~S}$ generation. 
A
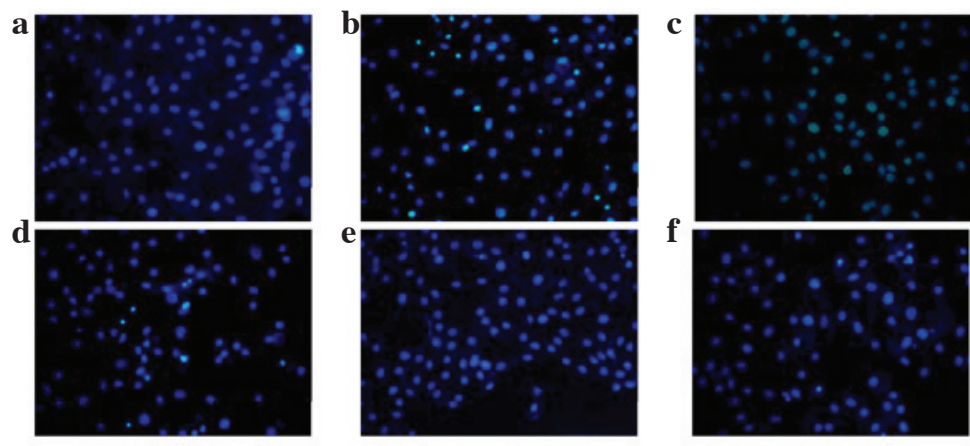

B

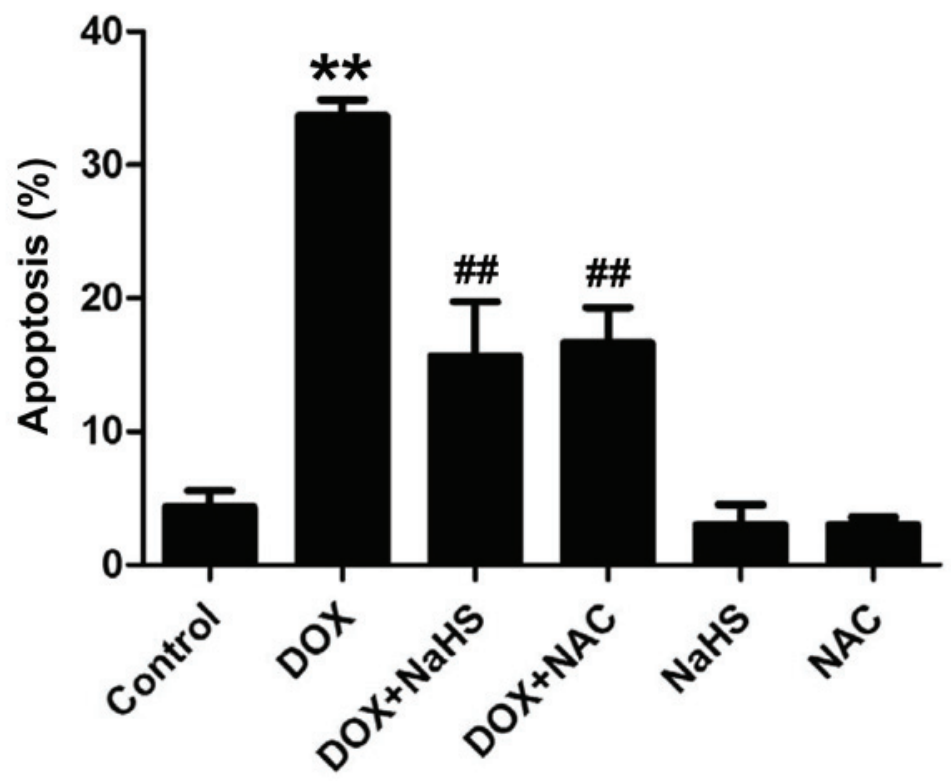

Figure 6. Exogenous $\mathrm{H}_{2} \mathrm{~S}$ and NAC reduce DOX-induced apoptosis in H9c2 cells. (A) Hoechst 33258 nuclear staining followed by fluorescence imaging was used to observe cell apoptosis. (a) Control group; (b) DOX group; (c) NaHS+DOX group; (d) NAC+DOX group; (e) NaHS group; (f) NAC group (magnification, $\mathrm{x} 40$ ). (B) Apoptotic rates were analyzed using a cell counter and ImageJ 1.41 software. The data are presented as the mean \pm standard error of the mean ( $\mathrm{n}=3$ ). ${ }^{* *} \mathrm{P}<0.01$, vs. control group; ${ }^{\# \#} \mathrm{P}<0.01$, vs. DOX-treated group. DOX, doxorubicin; NAC, N-acetyl-L-cysteine; NaHS, sodium hydrosulfide.

Prx III is a mitochondrial antioxidant protein and member of the Prx family, which is capable of catalyzing $\mathrm{H}_{2} \mathrm{O}_{2}$ reduction (31). In addition, the overexpression of Prx III has been demonstrated to protect neurons against oxidative stress-induced cell death (32). These beneficial effects make Prx III a valuable potential candidate for the treatment of left ventricular systolic dysfunction following myocardial infarction, in which the production of ROS has been observed to be increased in the mitochondria (21). Although several previous studies have shown the beneficial effects of antioxidants in heart failure $(33,34)$, investigations have not been performed to specifically examine the role of PrX III in DOX-induced cytotoxicity. The results of the present study demonstrated that the expression levels of Prx III were significantly increased in the DOX-induced H9c2 cell injury model. Similarly, an increase of Prx III was previously reported by $\mathrm{Xi}$ et al (35), and nitrate treatment restored the expression of Prx III. In the present study, the results demonstrated that the Prx III expression levels of Prx III increased following DOX treatment, and exogenous $\mathrm{H}_{2} \mathrm{~S}$ preconditioning suppressed the expression of Prx III, markedly attenuating DOX-induced apoptosis.
In previous years, several studies have demonstrated that ROS are important in the pathogenesis of cardiac failure (36-38). In addition, antioxidants have been reported to exert protective effects against heart failure (21). Oxidative stress is a primary mechanism by which DOX-induced cardiomyocyte injury (24). Notably, the present study demonstrated that oxidative stress was involved in DOX-induced cell injury, and further examined whether the activation of Prx III by DOX was due to the induction of ROS. It was shown that pre-treatment of the H9c2 cells with the NAC ROS scavenger significantly decreased DOX-induced expression levels of Prx III. Collectively, these results supported the hypothesis that the induction of ROS by DOX activates Prx III in H9c2 cells.

In conclusion, the principal finding of the present study was that $\mathrm{H}_{2} \mathrm{~S}$ inhibited DOX-induced apoptosis in the $\mathrm{H} 9 \mathrm{c} 2$ cells, and its effects may involve inhibition of the ROS-mediated expression of Prx III. The results of the present study not only improved current understanding of the mechanisms underlying $\mathrm{H}_{2} \mathrm{~S}$-mediated anti-apoptosis in cardiomyocytes, but they also provide valuable evidence in support of the potential use of $\mathrm{H}_{2} \mathrm{~S}$ as a treatment for cardiovascular diseases. 


\section{Acknowledgements}

The present study was supported by grants from the Medical Scientific Research Funds of the Guangdong province (grant no. A2014810) and the Graduate Student Research Innovation Project of the Hunan province (grant no. CX2013B397).

\section{References}

1. Menna P, Recalcati S, Cairo G and Minotti G: An introduction to the metabolic determinants of anthracycline cardiotoxicity. Cardiovasc Toxicol 7: 80-85, 2007.

2. Barry E, Alvarez JA, Scully RE, Miller TL and Lipshultz SE: Anthracycline-induced cardiotoxicity: Course, pathophysiology, prevention and management. Expert Opin Pharmacother 8: 1039-1058, 2007.

3. Jang WJ, Choi DY and Jeon IS: Vascular endothelial dysfunction after anthracyclines treatment in children with acute lymphoblastic leukemia. Korean J Pediatr 56: 130-134, 2013.

4. Truong J, Yan AT, Cramarossa G and Chan KK: Chemotherapy-induced cardiotoxicity: Detection, prevention and management. Can J Cardiol 30: 869-878, 2014.

5. Spagnuolo RD, Recalcati S, Tacchini L and Cairo G: Role of hypoxia-inducible factors in the dexrazoxane-mediated protection of cardiomyocytes from doxorubicin-induced toxicity. Br J Pharmacol 163: 299-312, 2011.

6. Guo R, Lin J, Xu W, Shen N, Mo L, Zhang $\mathrm{C}$ and Feng J: Hydrogen sulfide attenuates doxorubicin-induced cardiotoxicity by inhibition of the p38 MAPK pathway in $\mathrm{H} 9 \mathrm{c} 2$ cells. Int J Mol Med 31: 644-650, 2013

7. Gu J, Hu W and Zhang DD. Resveratrol, a polyphenol phytoalexin, protects against doxorubicin-induced cardiotoxicity. J Cell Mol Med 19: 2324-2328, 2015.

8. Karimi G, Ramezani M and Abdi A. Protective effects of lycopene and tomato extract against doxorubicin-induced cardiotoxicity. Phytother Res 19: 912-914, 2005.

9. Polhemus DJ and Lefer DJ: Emergence of hydrogen sulfide as an endogenous gaseous signaling molecule in cardiovascular disease. Circ Res 114: 730-737, 2014.

10. Zhang Y, Tang ZH, Ren Z, Qu SL, Liu MH, Liu LS and Jiang ZS Hydrogen sulfide, the next potent preventive and therapeutic agent in aging and age-associated diseases. Mol Cell Biol 33: 1104-1113, 2013

11. Huang YE, Tang ZH, Xie W, Shen XT, Liu MH, Peng XP, Zhao ZZ, Nie DB, Liu LS and Jiang ZS: Endogenous hydrogen sulfide mediates the cardioprotection induced by ischemic postconditioning in the early reperfusion phase. Exp Ther Med 4: 1117-1123, 2012.

12. Polhemus DJ, Calvert JW, Butler J and Lefer DJ: The cardioprotective actions of hydrogen sulfide in acute myocardial infarction and heart failure. Scientifica (Cairo) 2014: 768607, 2014.

13. Li C, Hu M, Wang Y, Lu H, Deng J and Yan X. Hydrogen sulfide preconditioning protects against myocardial ischemia/reperfusion injury in rats through inhibition of endo/sarcoplasmic reticulum stress. Int J Clin Exp Pathol 8: 7740-7751, 2015.

14. Sahu BD, Mahesh Kumar J and Sistla R. Baicalein, a Bioflavonoid, Prevents Cisplatin-Induced Acute Kidney Injury by Up-RegulatingAntioxidant Defenses and Down-Regulating the MAPKs and NF- $x$ B Pathways. PLoS One 10: e0134139, 2015.

15. Liu MH, Yuan C, He J, Tan TP, Wu SJ, Fu HY, Liu J, Yu S, Chen YD, Le QF, Tian W,Hu HJ,Zhang Y and Lin XL. Resveratrol protects PC12 cells from high glucose-induced neurotoxicity via PI3K/Akt/FoxO3a pathway. Cell Mol Neurobiol 35: 513-522, 2015.

16. Wood ZA, Poole LB and Karplus PA: Peroxiredoxin evolution and the regulation of hydrogen peroxide signaling. Science 300 650-653, 2003.

17. Poynton RA and Hampton MB: Peroxiredoxins as biomarkers of oxidative stress. Biochim Biophys Acta 1840: 906-912, 2014.

18. Jeong HJ, Jeong HW, Song SS, Kang JW, Seo JH, Lee YH, Lee KS and Kim DW: Upregulation of peroxiredeoxin III in the hippocampus of acute immobilization stress model rats and the Foxo3a-dependent expression in PC12 cells. Cell Mol Neurobiol 31: 1041-1046, 2011
19. Nemoto S, Combs CA, French S, Ahn BH, Fergusson MM, Balaban RS and Finkel T: The mammalian longevity-associated gene product $\mathrm{p} 66 \mathrm{shc}$ regulates mitochondrial metabolism. J Biol Chem 281: 10555-10560, 2006.

20. Chae HZ, Kim HJ, Kang SW and Rhee SG: Characterization of three isoforms of mammalian peroxiredoxin that reduce peroxides in the presence of thioredoxin. Diabetes Res Clin Pract 45: 101-112, 1999.

21. Matsushima S, Ide T, Yamato M, Matsusaka H, Hattori F, Ikeuchi M, Kubota T, Sunagawa K, Hasegawa Y, Kurihara T, et al: Overexpression of mitochondrial peroxiredoxin-3 prevents left ventricular remodeling and failure after myocardial infarction in mice. Circulation 113: 1779-1786, 2006.

22. Chang TS, Cho CS, Park S, Yu S, Kang SW and Rhee SG: Peroxiredoxin III, a mitochondrion-specific peroxidase, regulates apoptotic signaling by mitochondria. J Biol Chem 279: 41975-41984, 2004.

23. Kimura H: Hydrogen sulfide: its production, release and functions. Amino Acids 41: 113-121, 2011.

24. Guo R, Wu K, Chen J, Mo L, Hua X, Zheng D, Chen P, Chen G, $\mathrm{Xu} \mathrm{W}$, Feng $\mathrm{J}$, et al: Exogenous hydrogen sulfide protects against doxorubicin-induced inflammation and cytotoxicity by inhibiting p38MAPK/NFkappaB pathway in H9c2 cardiac cells. Cell Physiol Biochem 32: 1668-1680, 2013

25. Wang X, Wang XL, Chen HL, Wu D, Chen JX, Wang XX, Li RL, He JH, Mo L, Cen X, et al: Ghrelin inhibits doxorubicin cardiotoxicity by inhibiting excessive autophagy through AMPK and p38-MAPK. Biochem Pharmacol 88: 334-350, 2014

26. Ji Y, Pang QF, Xu G, Wang L, Wang JK and Zeng YM: Exogenous hydrogen sulfide postconditioning protects isolated rat hearts against ischemia-reperfusion injury. Eur J Pharmacol 587: 1-7, 2008.

27. Osipov RM, Robich MP, Feng J, Liu Y, Clements RT, Glazer HP, Sodha NR, Szabo C, Bianchi C and Sellke FW: Effect of hydrogen sulfide in a porcine model of myocardial ischemia-reperfusion: Comparison of different administration regimens and characterization of the cellular mechanisms of protection. J Cardiovasc Pharmacol 54: 287-297, 2009.

28. Sodha NR, Clements RT, Feng J, Liu Y, Bianchi C, Horvath EM, Szabo C and Sellke FW: The effects of therapeutic sulfide on myocardial apoptosis in response to ischemia-reperfusion injury. Eur J Cardiothorac Surg 33: 906-913, 2008.

29. Pan TT, Feng ZN, Lee SW, Moore PK and Bian JS: Endogenous hydrogen sulfide contributes to the cardioprotection by metabolic inhibition preconditioning in the rat ventricular myocytes. J Mol Cell Cardiol 40: 119-130, 2006.

30. Bian JS, Yong QC, Pan TT, Feng ZN, Ali MY, Zhou S and Moore PK: Role of hydrogen sulfide in the cardioprotection caused by ischemic preconditioning in the rat heart and cardiac myocytes. J Pharmacol Exp Ther 316: 670-678, 2006.

31. Song IS, Kim HK, Jeong SH, Lee SR, Kim N, Rhee BD, Ko KS and Han J: Mitochondrial peroxiredoxin III is a potential target for cancer therapy. Int J Mol Sci 12: 7163-7185, 2011.

32. Hattori F, Murayama N, Noshita T and Oikawa S: Mitochondrial peroxiredoxin-3 protects hippocampal neurons from excitotoxic injury in vivo. J Neurochem 86: 860-868, 2003.

33. Betge S, Lutz K, Roskos M and Figulla HR: Oral treatment with probucol in a pharmacological dose has no beneficial effects on mortality in chronic ischemic heart failure after large myocardial infarction in rats. Eur J Pharmacol 558: 119-127, 2007.

34. Jain AK, Mehra NK and Swarnakar NK. Role of Antioxidants for the Treatment of Cardiovascular Diseases: Challenges and Opportunities. Curr Pharm Des 21: 4441-4455, 2015.

35. Xi L, Zhu SG, Hobbs DC and Kukreja RC: Identification of protein targets underlying dietary nitrate-induced protection against doxorubicin cardiotoxicity. J Cell Mol Med 15: 2512-2524, 2011

36. Schwarzer M, Osterholt M, Lunkenbein A, Schrepper A, Amorim P and Doenst T: Mitochondrial reactive oxygen species production and respiratory complex activity in rats with pressure overload-induced heart failure. J Physiol 592: 3767-3782, 2014.

37. Münzel T, Gori T, Keaney JF Jr, Maack C and Daiber A. Pathophysiological role of oxidative stress in systolic and diastolic heart failure and its therapeutic implications. Eur Heart J 36: 2555-2564.

38. Zuo L, Chuang CC, Hemmelgarn BT and Best TM. Heart failure with preserved ejection fraction: Defining the function of ROS and NO. J Appl Physiol 119: 944-951, 2015. 